\title{
CRISIS DE LA NOCIÓN DE AUTORIDAD
}

\author{
Adriana María Ruiz GutiérRez \\ doi:10.11144/Javeriana.uph34-68.crna
}

\section{RESUMEN}

Este artículo se centra en las distintas relaciones entre la auctoritas y la potestas como figuras esenciales del derecho positivo, las cuales se expresan en dos ámbitos: por un lado, como fuentes de creación y protección del orden jurídico-institucional y, por otro, como fuentes de negación y destrucción de la vida humana. La auctoritas acrecienta considerablemente la potestas allí donde se exige la protección del orden y, por lo mismo, aumenta radicalmente el poder de destrucción de la vida humana. El derecho y la vida constituyen, pues, el fundamento y el objeto último del vínculo íntimo y complejo entre auctoritas y potestas, objetivándose en la conservación del derecho y, a su vez, en la saturación jurídico-política de la vida humana, hasta reducirla a nuda vida, esto es, a un objeto sin valor que puede ser gestionado, administrado y, finalmente, eliminado. Bajo estas premisas, este trabajo pretende ocuparse, entonces, de las relaciones entre auctoritas y potestas, y entre estas y la nuda vida, a partir de los distintos análisis y resultados históricos, políticos y jurídicos. Estos análisis permiten afirmar bien sea la supremacía del nexo entre autoridad y poder para garantizar la vigencia del orden jurídico-institucional, o la supremacía de la vida humana capaz de liberarse del exceso de dicho nexo.

Palabras clave: auctoritas; potestas; violencia; vida

Universidad de San Buenaventura, Medellín, Colombia.

Correo electrónico: adriana.ruiz@upb.edu.co

Para citar este artículo: RuIz GutiérREZ, A.M. (2017). Crisis de la noción de autoridad. Universitas Philosophica, 34(68), pp. 143-172. ISSN 0120-5323, ISSN en línea 2346-2426. doi:10.11144/ Javeriana.uph34-68.crna

Este artículo se realiza en el marco de la investigación "Derecho y violencia: de la teología política a la biopolítica" (radicado 449011.16.P.05). 


\title{
CRISIS OF THE NOTION OF AUTHORITY
}

\author{
Adriana María Ruiz Gutiérrez
}

\begin{abstract}
This article focuses on the different relationships that bond the concept of auctoritas with the concept of potestas as essential notions of positive law, which are expressed in two areas: as sources of creation and protection of the legal and institutional order and as sources of denial and destruction of human life. Auctoritas considerably increases potestas when protection of order is required and, therefore, radically increases the power of destruction of human life. Law and life, then, are the foundation and the ultimate object of this intimate and complex link between auctoritas and potestas, objectified in the preservation of the law and, in turn, saturating the legal and political dimensions of human life, reducing it to bare life, that is, to a worthless object that can be managed, administered and eventually eliminated. Upon these premises, this paper aims to address the relations between auctoritas and potestas, and between them and the bare life, from the various analyzes and historical, political and legal outcomes. These analyzes allow us to state either the supremacy of the link between authority and power to ensure the validity of the legal and institutional order, or the supremacy of human life, free from this excessive link.
\end{abstract}

Key words: auctoritas; potestas; violence; life 


\section{Planteamiento de la cuestión}

LA FILOSOFÍA DEL DERECHO se encuentra constituida por un conjunto de nociones que, pese a su aparente claridad y consistencia respecto a la tradición, se tornan ambiguas no solo en su sentido lógico, sino también, y más que nada, en su sentido práctico. Por esta razón, algunos conceptos que, al mismo tiempo, conforman las imágenes del derecho, tales como soberanía, poder, violencia, constitución, consenso, disenso, conflicto, democracia, orden, anarquía, entre otros, constituyen los objetos de variadas investigaciones filosóficas y jurídicas que intentan descubrir y esclarecer los sentidos, las confusiones, las antinomias e, incluso, las aporías de dichas nociones respecto al pasado y el presente histórico. La categoría de autoridad (auctoritas) -en crítica dialéctica respecto a la noción de poder (potestas) - integra una de tantas nociones que presentan no pocas dificultades en relación con su significado y sus efectos en el campo jurídico-político. Al respecto, Giorgio Agamben, en su libro Estado de excepción: Homo sacer II, 1 , advierte que la categoría de auctoritas parece chocar con obstáculos y aporías casi insuperables en la filosofía y la teoría política, así como en la historia del derecho (2004, p. 109). Agamben coincide aquí con otros pensadores que, sin obviar, naturalmente, sus distintas perspectivas y sus alcances, señalan los inconvenientes de definir el concepto de auctoritas, bien sea por las confusiones teóricas y prácticas en relación con la categoría de potestas, o por su contenido fragmentario, tanto jurídico -privado y público-, como teológico, político y sociológico, al que ha dado lugar en la reflexión y en la praxis política de Occidente (Passerin D' Entrevès, 2001; Jouvenel, 1957; Arendt, 1996, 2010a; Weber, 1964; Schmitt, 1996; García, 1983; D’Ors, 1980, 1984; Fueyo, 1953, 1961; Domingo, 1997, 1999; Sartori, 1993; Casinos, 1999; Clemente, 2009).

Pero el sentido de auctoritas se torna aún más confuso debido a su relación de proximidad y, al mismo tiempo, de identidad con otras categorías que son utilizadas, la mayor de las veces, como términos análogos, a saber: poder, fuerza, coerción, violencia, autorización, entre otras. En este sentido, Giovanni Sartori (1993, p. 120) afirma que todo el campo semántico de las ciencias sociales constituido por términos como poder, autoridad, influencia y coerción se encuentra actualmente en máximo desorden. Mario Stoppino (2011) coincide en afirmar que la situación actual del término auctoritas tanto en su definición como en sus 
usos es bastante compleja e intrincada, no solo en razón a sus estrechas relaciones con el concepto de poder, sino también en razón a sus distintas reinterpretaciones históricas, a menudo con significados notoriamente distantes. En la misma perspectiva, en su trabajo Sobre la violencia, Hannah Arendt (2010a) se esfuerza por delimitar los contornos y, por supuesto, las diferencias específicas entre las categorías de poder, fuerza, violencia y autoridad; ya que la crisis de la ciencia política y, más en particular, del derecho contemporáneo, surge precisamente en razón de las enunciaciones imprecisas y los usos equivocados de sus propios términos. Según Arendt (2010a, p. 62), auctoritas alude al fenómeno jurídico-político más esquivo y, por eso, como término, al más ambiguo y desconocido. En palabras de la filósofa alemana, tan reveladoras como las de Agamben y otros pensadores contemporáneos, "ya no estamos en condiciones de saber qué es realmente la autoridad” (Arendt, 1996, p. 101).

Partiendo de esta complejidad, los romanistas españoles Jesús Fueyo, Álvaro D’Ors, Rafael Domingo, Javier Casinos y Ana Isabel Clemente elaboran una genealogía del concepto de autoridad en el derecho romano, tanto privado como público, reseñando sus distintas crisis en la historia del pensamiento jurídico y su necesaria rehabilitación en el derecho contemporáneo. Dichos autores concuerdan en la idea según la cual la absorción de la auctoritas por parte de la potestas constituye la clave constitucional del principado de Augusto, así como la posterior divinización de la autoridad de los emperadores romanos, alcanzando su mayor desarrollo durante la época moderna. La Modernidad asistió a la invención del Estado y a su concepto fundamental de soberanía, en el cual concurren indistintamente auctoritas y potestas, generando así la más grave inconsistencia filosófica y jurídica de la teoría moderna del Estado (Fueyo, citado en Agamben, 2004, p. 111). D’Ors y Domingo derivan un problema mayor de la interrelación entre ambos términos, esto es, la tendencia real o potencial de una persona que poseyendo autoridad pretende llegar a ser potestad ${ }^{1}$ o quien detentado potestad

1 Álvaro D’Ors (citado en Domingo, 1997, p. 191) contrapone el saber socialmente reconocido (auctoritas) y el poder socialmente reconocido (potestas) a partir del simbolismo de la mano: "el puño cerrado evidencia la fuerza, el poder, y es símbolo de la revolución. El puño abierto mostrando la palma es el símbolo del poder ya reconocido, es decir, de la potestad; es, por eso, el que utilizó Hitler en la época nacionalsocialista. Un dedo levantado simboliza el saber; el niño sabiondo que sabe dar respuestas a la pregunta que ha hecho el maestro en la escuela levanta un dedo -absolutamente inofensivo-, porque carece de poder. Dos dedos levantados -el índice y el corazón- sim- 
procura ser investido de autoridad, es decir, la confusión de quien conservando funciones consultivas y de control derivadas de los atributos de autoridad, asume, asimismo, funciones legislativas y ejecutivas propias de la potestad, y viceversa (D’Ors, 1984, p. 378; Domingo, 1997, pp. 191-192). Por esta razón, ambos teóricos reclaman un concepto de autoridad separada del poder, toda vez que la subordinación de la auctoritas a la potestas no solo disminuye su sentido, sino también su función limitadora del poder.

De la misma manera, en su ensayo ¿Qué es la autoridad?, Hannah Arendt (1996, pp. 101-104) intenta explicar qué significó la idea de autoridad en el mundo grecorromano, toda vez que la actualidad de dicha noción se torna confusa en razón a sus múltiples y profundas crisis en la teoría y la praxis jurídicopolítica moderna. Según Arendt, pese a la importancia de la noción de autoridad en la teoría y, más en general, en la historia de las ideas jurídicas, el concepto de auctoritas tal como se conocía en la tradición ha desaparecido y, en su lugar, los restos de dicho término se hacen cada vez más complejos e indiscernibles en la comprensión de ciertas experiencias contemporáneas. Arendt se refiere, en sentido estricto, a los gobiernos europeos totalitarios del siglo $\mathrm{XX}$, cuyas acciones fueron devastadoras para ciertas autoridades tradicionales, tales como el padre y el maestro en su relación con el hijo y el discípulo, respectivamente. Arendt subraya además las imprecisiones y los equívocos que califican de autoritarios al nazismo alemán y el bolchevismo soviético. En efecto, dichos fenómenos produjeron un dominio de los hombres sobre los hombres desconocido hasta entonces en la experiencia política de Occidente, puesto que exigieron no solo el cumplimiento de los mandatos, sino también la convicción absoluta de obediencia.

En su trabajo sobre la Teoría de la constitución, Carl Schmitt (1996) también se ocupa del término de auctoritas en oposición dialéctica y, a su vez, en relación

\footnotetext{
bolizan el saber reconocido, es decir, la autoridad. Así, en las miniaturas medievales, es frecuente representar a las personas que hablan -que están ejerciendo, por tanto, su autoridad- con estos dos dedos levantados. Así también, en los iconos bizantinos -modelo de la imaginería medieval universal-, Jesucristo lleva en su mano izquierda el globo del mundo que domina, y levanta dos dedos de su mano derecha en señal de su autoridad. El problema llega cuando el que tiene dos dedos levantados quiere levantar los tres restantes, es decir, cuando la autoridad pretende llegar a ser potestad (gobierno platónico de los sabios) o, lo que es peor, cuando el gobernante que tiene la palma de la mano extendida, como tiene los cinco dedos levantados, piensa que está revestido, no solo de auctoritas, sino también de potestas".
} 
de complementariedad con la noción de potestas. Según el jurista alemán, ambas nociones prestan una importancia definitiva en la teoría general del Estado y, particularmente, de la constitución, así como en el esclarecimiento de ciertos problemas de derecho internacional. Schmitt, al igual que Hannah Arendt, y sin desconocer sus distintas comprensiones sobre los sentidos y los fines de las nociones jurídico-políticas, distingue los términos de auctoritas y potestas en relación con el tiempo, ya que mientras el poder se sirve de femémonos como soberanía y majestad para perseverar el orden mediante el uso de la fuerza presente o futura en vista de la necesidad política, la autoridad, en cambio, alude a un prestigio basado esencialmente en el elemento de la continuidad, esto es, en la tradición y la permanencia propias del pasado fundador. En Schmitt (1996), sin embargo, y pese a la evidente oposición entre ambos términos, tanto la fuerza como la autoridad "son plenamente eficaces y vivas, una junto a otra, en todo Estado” (p. 93). Según Schmitt, toda autoridad requiere de la fuerza a fin de lograr su permanencia en el tiempo y toda fuerza precisa de la legitimidad que se deriva de la autoridad con el propósito de obtener la obediencia. Aquí reside, justamente, el vínculo de necesidad y de complementariedad entre ambos términos. Auctoritas, empero, adolece de una definición exacta: "es una palabra que se sustrae a toda definición rigurosa [...], la palabra designa algo 'ético-social', una 'posición' de rara mezcla entre fuerza política y prestigio social” (Schmitt, 1996, p. 93).

Schmitt se sirve entonces de una breve genealogía en el derecho público romano y en el derecho canónico medieval para distinguir las nociones de poder y autoridad y, más en particular, los sujetos de una y otra. Según Schmitt, es cierto que en Roma, el Senado tenía auctoritas y el pueblo poseía potestas e imperium. A pesar de su posterior carencia de fuerza y después de que el poder del pueblo romano hubiera sucumbido bajo el Imperio, el Senado conservó su autoridad y se convirtió, por último, durante la época imperial, en la única instancia que todavía podía prestar algo a manera de legitimidad. Posteriormente, el papa romano se arrogó, en un sentido especial, auctoritas -no potestas- frente al emperador, mientras que este tenía potestas. Las expresiones de la carta de San Gelasio I al emperador Anastasio del año 494, son decisivas en la relación entre auctoritas y potestas respecto al gobierno del ordo mundi que, por lo demás, domina la gran polémica de los siglos X y XI: "Duo sunt quibus principaliter mundus hic regitur: auctoritas sacra pontificum et regalis potestas" (Schmitt, 1996, p. 93). Pero Schmitt avanza 
aún más en su genealogía hasta comprender la teoría y la praxis moderna y contemporánea. En efecto, en su trabajo sobre La defensa de la constitución: estudio acerca de las diversas especies y posibilidades de salvaguardia de la constitución, Schmitt (1996) trata de definir el poder neutral del presidente del Reich en el estado de excepción por medio de la contraposición dialéctica entre auctoritas y potestas. Luego de objetar severamente los postulados de la teoría liberal del Estado y el derecho, llega a lamentar la confusión entre autoridad y dictadura.

Giorgio Agamben también alude a la relación entre auctoritas y potestas, a propósito de su investigación sobre el estado de excepción. Luego de realizar una breve genealogía histórica y filológica de la noción de auctoritas, el filósofo italiano insiste en el vínculo de exclusión y, al mismo tiempo, de complementariedad entre ambas nociones. En este punto, Agamben (2004, pp. 114, 124) señala la estructura dual y, por lo mismo, fundamental del sistema jurídico occidental, compuesto por dos elementos claramente distintos que, sin embargo, forman de consuno un sistema binario: potestas, que en sentido estricto constituye una figura normativa y jurídica, y auctoritas, que en sentido amplio conforma un elemento anómico y metajurídico. Pero ¿cuál es más exactamente la relación entre una y otra? ¿Cómo se integran, excluyen y perfeccionan una respecto a la otra? La aprehensión de dicha conexión revela no solo la aporía misma del orden jurídico, cuya protección exige su propia suspensión, sino también el más extremo y complejo de los vínculos jurídico-políticos gestados en virtud de la necesidad. Porque es en las situaciones límite o circunstancias excepcionales donde los nexos entre auctoritas y potestas cobran toda su legibilidad y transparencia:

La auctoritas parece actuar como una fuerza que suspende la potestas donde esta se ejerce y la reactiva donde ya no estaba en vigor. Es un poder que suspende o reactiva el derecho, pero que no está vigente formalmente como derecho. (Agamben, 2004, p. 116)

De modo que la auctoritas puede afirmarse únicamente en una relación de validación o suspensión de la potestas, cuyo resultado genera la mayoría de las veces la corrupción y la catástrofe del propio orden jurídico que pretexta conservar. Pero Agamben avanza aún más en la relación entre auctoritas y potestas haciendo notar sus vínculos con la vida misma. Según Agamben, aquí se puede hablar en sentido exacto del carácter originariamente biopolítico del paradigma de auctoritas, porque "la norma puede aplicarse al caso normal y puede ser suspendida sin 
anular integralmente el orden jurídico, porque, en la forma de la auctoritas o de la decisión soberana, se refiere inmediatamente a la vida, surge de ella" (Agamben, 2004, p. 124). Por consiguiente, toda suspensión del orden jurídico genera inmediatamente la aprehensión y, en consecuencia, la administración y la anulación de la vida humana. Agamben (2004, pp. 122, 125-126) demuestra esta afirmación mediante el funcionamiento paralelo de los dispositivos jurídicos de la auctoritas empleados desde la Roma republicana y la Europa medieval hasta la Primera Guerra Mundial, por vía del fascismo y del nacionalismo hasta nuestros días (véanse también: 2005, 2006, 2010). Dichos dispositivos de gobierno revelan, pues, el vínculo tan íntimo como complejo entre el derecho y la violencia y, por consiguiente, entre la violencia jurídica y la nuda vida (Ruiz, 2013). De ahí que la nuda vida sea un producto de la máquina jurídico-estatal y no algo que la preexista. $\mathrm{Al}$ igual que Schmitt, aunque con importantes diferencias, Agamben concluye su investigación mostrando el nexo entre la política y el derecho. Según el autor, "la política ha sufrido un eclipse duradero porque ha sido contaminada por el derecho, y se ha concebido a sí misma, en el mejor de los casos, como poder constituyente (es decir, violencia que establece el derecho)" (Agamben, 2004, p. 127).

En suma, el concepto de auctoritas presenta graves problemas e inconsistencias tanto teóricas como prácticas, pero las imprecisiones son mayores si se tiene en cuenta la vaguedad del fundamento etimológico de auctoritas y sus distintas aplicaciones tanto en el derecho privado como en el derecho público romano. En su Vocabulario de las instituciones indoeuropeas, Emile Benveniste asocia auctor y auctoritas, señalando las ambigüedades de ambas nociones. El término auctor, y el de su abstracto auctoritas, proviene del término indoeuropeo augeo, traducido comúnmente como acrecentar o aumentar (Fueyo, 1961; D’Ors, 1980, 1984; Domingo, 1997; Casinos, 1999). Pero esta definición es apenas satisfactoria, ya que resulta extraña e incluso incompatible con el sentido primero de la raíz aug- que designa fuerza -además, scr. ojas, como av. aojab- y sus derivados, indican particularmente la fuerza de los dioses; el adjetivo av. aojahvant, dotado de fuerza, es una calificación exclusivamente divina (Benveniste, 1969, p. 326)-. Sin embargo, se sigue traduciendo augeo como aumentar, incrementar, hacer mayor algo que ya existe, lo cual resulta exacto en la lengua clásica, pero erróneo en la tradición más arcaica. Según Benveniste (1969), "una amplia porción del sentido de augeo permanece aún en la sombra, y es precisamente la porción esencial, aquella de la que 
proceden las determinaciones especiales que han terminado por escindirse en unidades distintas" (p. 326). En sus usos más antiguos, augeo no indica el hecho de aumentar, sino el acto de creación que hace surgir algo de un medio nutricio, el cual es propio de los dioses o de las grandes fuerzas de la naturaleza, no de los hombres. Esta acepción encuentra su fuente en Lucrecio (citado en Benveniste, 1969, p. 326), quien valoriza con insistencia el término de auctoritas al trazar la génesis de la vida y la muerte: "quodeumque alias ex se res auget alitque (todo cuerpo que hace nacer de sí y alimenta otras cosas)" (V, 322); “morigera ad fruges augendas atque animantis (dócil para hacer nacer las plantas y los seres)” (V, 80).

En este sentido, auctor es quien toma una iniciativa, promueve, funda, cultiva, garantiza por vez primera alguna actividad. Y auctoritas es el acto de producción o el poder de iniciativa. A augeo también corresponde la noción religiosa de augur, la cual habría designado la "promoción" otorgada por los dioses a una empresa y manifestada por un presagio. Esto confirma que la acción de augere es de origen divino. De augur se deriva asimismo el adjetivo de augustus, "provisto de augus, es decir, dotado de ese acrecentamiento divino" (Benveniste, 1969, p. 326). De esta manera, el sentido primero de augeo se encuentra nuevamente por medio de auctor en auctoritas: "toda palabra pronunciada con la autoridad determina un cambio en el mundo, crea algo" (Benveniste, 1969, p. 326). Esta cualidad misteriosa es lo que augeo expresa, el poder que hace surgir las plantas o que da existencia a una ley. El auctor es el único que promueve, porque solo él está dotado de esa cualidad que el indio llama ojah. En palabras de Benveniste (1969), el significado corriente de aumentar es apenas un sentido secundario y débil de augeo: "valores oscuros y poderosos permanecen en esa auctoritas, ese don, reservado a pocos hombres, de hacer surgir algo y -al pie de la letra- de "hacer existir"' (p. 327). En suma, puede decirse que, en conjunto, auctoritas alude al poder ofuerza originaria de crear, fundar, fabricar, hacer algo nuevo. Sin embargo, el jurista Álvaro D’Ors objeta esta comprensión arcaica de auctoritas como fuerza y, en cambio, la define como saber o prestigio socialmente reconocido, en oposición a la potestas entendida como poder socialmente reconocido (D’Ors, 1984; Domingo, 1997; Casinos, 1999; Clemente 2009). Esta acepción es propia de la comprensión latina del término, especialmente del periodo republicano. Justamente, porque

la corrupción de auctoritas por su contaminación con potestas ha consistido precisamente en llamar autoridad a la instancia superior de la potestad, de la 
que las otras potestades derivan por delegación, y a la que sirven como "agentes" ejecutivos, los agentes de la autoridad. (D’Ors, 1984, p. 378)

Pero a la comprensión indoeuropea de la auctoritas como poder o fuerza originaria de creación y de la latina como saber o prestigio socialmente reconocido, se agrega la acepción moderna del término entendido como poder originario de mandar y hacerse obedecer. Estos giros y discontinuidades en el sentido y el uso etimológico del término se complican aún más en la fenomenología jurídicopolítica, ya que dicha noción corresponde a una experiencia histórica especialmente amplia.

\section{Auctoritas en la praxis jurídico-política romana}

EN EL DERECHO PRIVADO ROMANO, el sentido de la auctoritas se expresa en la interpositio del paterfamilias o del tutor, quien interviene para conferir validez jurídica a los actos de aquellos que por sí mismos no gozan de capacidad jurídica, así como los menores o los incapaces. Agamben (2004, p. 111) subraya, empero, que la auctoritas en su forma tradicional privatista no alude necesariamente a la idea representación moderna, en virtud de la cual se imputan al mandante los actos realizados por su mandatario o su representante legal; sino a la condición de sui juris del pater o del tutor. A diferencia del derecho privado, en el derecho público romano la noción de auctoritas se presenta, sin embargo, bastante confusa, ora porque su sentido y sus finalidades se confunden con términos análogos como potestas, ora porque el nexo entre auctoritas y potestas hace borrosas las limitaciones y los alcances de una y otra, ora porque auctoritas se transforma en potestas en manos de una misma persona, cargo, institución, o viceversa (García, 1983, pp. 138139). Basta observar algunos episodios históricos para advertir, justamente, cómo ambas nociones se complementan hasta hacerse indiscernibles incluso para ellas mismas. En la historia del principado romano Augusto, por ejemplo, y en lo sucesivo otros tantos emperadores gobernaron bajo una idea de auctoritas coextensiva a la del Senado, convertido típicamente en la voz del emperador.

Los emperadores romanos pretextaron su gobierno bajo la restauración y conservación de la constitución republicana, para lo cual se arrogaron una serie de facultades monárquicas que, no obstante, contradecían la misma constitución. Cierto es que mientras la auctoritas de los emperadores no era conferida ni 
definida por el Senado ni por las asambleas, su autoridad era dada por periodos sujetos a renovación, tal como ocurría con la figura del dictador, cuyos amplios poderes cesaban una vez se superara la crisis en el orden de la república. Sin embargo, la potestas concedida al emperador se prolongó tanto hasta habilitarlo para crear derecho y, a su vez, la auctoritas no solo fundamentó su poder, sino que sirvió para acrecentarlo ilimitadamente. De manera que los mandatos de los emperadores estaban por fuera y por encima del orden republicano que, sin embargo, debían completar y proteger (Kunkel, 1996, p. 56; García, 1983, pp. 154-155). Posteriormente, la autoridad de reyes y emperadores fue sustituida por la auctoritas del papa, quien se encontraba, no obstante, por fuera y por encima de la misma Iglesia, cuya existencia y conservación dependía de la propia ordenación papal (Ullmann, 1971, p. 73). El papa justificaba su auctoritas afirmándose no solo como el único mediador entre el cielo y la tierra, Dios y los hombres, sino también como aquél que conocía los mandatos de la divinidad expresados en el derecho canónico, respecto al cual podía ejercer amplios poderes de creación, interpretación y ejecución. El papa podía, entonces, decir sobre el derecho sin estar sujeto al mismo, ni a ninguna autoridad temporal.

Ambos ejemplos de autoridad se desarrollan bajo momentos agudos de crisis institucional y se intensifican en momentos posteriores a la normalización, porque la crisis es, por lo general, la forma en que la auctoritas se amplía y se perfecciona continuamente en relación con la potestas. De manera que no existen dos historias diferentes, una sobre la auctoritas y otra sobre la potestas, sino una sola, la de la auctoritas como una forma de potestas. El poder necesita de la autoridad para garantizar su eficacia en el tiempo, ya que percibe permanentemente el riesgo de su destrucción mediante la resistencia y la revolución, y la autoridad, por su parte, requiere del poder para extender su capacidad de ordenación de forma ilimitada. En la medida en que el portador de la auctoritas goce de la potestas y viceversa, tendrá mayor capacidad de decisión y medios de coacción extremos para crear y garantizar la existencia del orden jurídico-institucional, así como para gestionar la vida de los individuos que lo componen. La confusión entre los términos de auctoritas y potestas, así como sus efectos concretos en la vida de los hombres, constituye, pues, un asunto de primer orden en la teoría jurídica, no solo en lo que respecta a la definición e identificación del sujeto de la soberanía, 
sino también, y más que nada, en lo que concierne a la formación de sus amplias y prolongadas facultades respecto al derecho y a la vida humana.

Las nociones de auctoritas y potestas constituyen los dos vectores fundamentales de la dialéctica filosófico-política romana. En palabras de Domingo (1997, p. 184) y Casinos (1999, p. 85), en el término auctoritas se revela, principalmente, el carácter genuino de la política romana, ya que en el griego clásico no existe ningún vocablo equivalente al que se pueda verter satisfactoriamente dicha noción. En los primeros desarrollos de la política romana se gestan y dinamizan las relaciones de reciprocidad entre autoridad y poder como elementos indispensables del ethos romano, esto es, de toda su experiencia histórica, política y, especialmente, religiosa (Casinos, 1999, p. 91). Según Casinos, la religión ocupaba un lugar fundamental tanto en los asuntos públicos como en los privados, lo cual explica sus íntimas conexiones con las nociones jurídico políticas, tales como auctoritas y potestas. La primera se basa en la comprensión social de que existen ciertos sujetos investidos de una razón superior, cuyo reconocimiento se fundamenta en cierta fuerza mística idéntica a la potencia religiosa. La segunda, en cambio, representa el poder del hombre respaldado por la fuerza y la coacción de las armas e instituciones. De modo que la autoridad "aparece como algo que trasciende al hombre común, al ciudadano; es un factor de ordenación social previo e incontestable, que está por encima de las vicisitudes y de las lides humanas, que, en definitiva, se vincula a la religión" (Casinos, 1999, p. 89; Arendt, 1996, pp.131-132).

Las distinciones entre auctoritas y potestas coinciden, en principio, con los primeros fundamentos jurídico-políticos de la constitución republicana de la Roma clásica, en los cuales se advertían las diferencias prácticas entre imperium, potestas y auctoritas. La asociación romana se formó por el concurso libre de sus aldeanos, quienes eran hombres libres e iguales, sin nobleza instituida de derecho divino. La comunidad política adoptó entonces las formas propias de la familia y, en consecuencia, eligió un gran jefe que representaba el poder y la unidad de la familia política (Mommsen, 2003, pp. 89-90). El rey se denominaba rex, no porque gobernara bajo el concepto jurídico, sino porque dictaba sus órdenes (dictador) y mandatos en el sentido de su pleno poder y, en virtud de su función de mandar, organizar y mantener el orden interior y exterior, se le confiere el poder pleno para cumplir su encargo y las facultades ilimitadas del imperium. La noción de imperium se define, pues, como el mando militar supremo tanto en 
tiempos de guerra como en tiempos de paz que comprendía básicamente el derecho de vida y muerte (gladii potestas), además de otras facultades derivadas de su carácter como padre de la familia política, tales como: juzgar y castigar, imponer penas de policía, conocer en las causas civiles y penales, condenar a la pérdida de la libertad (Mommsen, 2003, p. 90; Ihering, 2001, p. 179). Pese a los atributos supremos del rey sobre el pueblo, este nunca se confundió con Dios, tal como ocurría entre los egipcios y los orientales. El rey era, en sentido estricto, el propietario de la ciudad. La potestas, por su parte, era el poder de mandar particularizado, esto es, confiado a una magistratura particular, a fin de cumplir con las funciones encargadas: potestas consular, tribunicia, popular, entre otras. En términos de derecho público, la potestas equivale a la competencia. Todos los magistrados tenían potestas, pero solo algunos poseían el poder coercitivo del imperium.

En campaña militar (militae) el magistrado dotado de imperium tenía la facultad de aplicar, según sus propias consideraciones, penas corporales al ciudadano transgresor y podía incluso hacerlo ejecutar. Sin embargo, el poder coercitivo de los magistrados que tenían imperium tenía un límite en el veto (intercessio) que podían proponer otros magistrados con igual rango o superior, así como los tribunos. Cuando el rey o, posteriormente, los magistrados con imperium marchaban, los lictores o alguaciles les acompañaban con las fasces, esto es, un haz formado por treinta varas atadas y un hacha, cuya figura constituía la expresión simbólica del imperium conferido a una persona o a un cargo en particular (García, 1983, p. 140; Kunkel, 1996, p. 24). La auctoritas, finalmente, se deriva de la palabra auctor, que designa el sujeto de la autoridad capaz de comenzar, fundamentar y desarrollar acciones, decisiones y juicios originados en los demás. Desde el punto de vista jurídico-político, auctor es quien posee la auctoritas y, como tal, puede cimentar o ratificar una decisión, pero sin formularla ni ejecutarla necesariamente, ya que ambos actos corresponden a la potestas. En consecuencia, "tiene auctoritas quien por su iniciativa o ratificación legítima, fundamenta y, por tanto, garantiza y acrece los actos de potestad” (García, 1983, p. 144).

En Roma, la auctoritas es poseída por un hombre o una asamblea de hombres en virtud de un cargo o una institución. La auctoritas que se deriva de un cargo depende más de la dignitas del cargo mismo que de la persona que lo ocupa. Aún más, el cargo tiene adscrito tal prestigio y dignidad que irradia sobre la persona que lo ocupa el mismo carácter. En el caso del Senado (Senatus), la 
auctoritas patrum constituía un atributo derivado de la sabiduría y la seriedad atribuida a los senadores, quienes emitían consejos y recomendaciones sobre lo que debía hacerse (García, 1983, p. 144; Mommsen, 2003, pp. 92-94; Grimmal, 1999, p. 73). Asimismo, ratificaban las decisiones proferidas por otros órganos. Empero, el Senado no poseía ni potestas, ni imperium por lo que sus recomendaciones no constituían órdenes ni mandatos; sin embargo, los magistrados, aunque no estuvieran vinculados jurídicamente a dichos consejos, debían obedecerlos so pena de arruinar su carrera política. El Senado constituyó, pues, el centro de gobierno romano, aunque carecía del mando directo respecto al pueblo y de los medios de coacción para ejecutar sus decisiones. Desde el punto de vista mágico, el Senado poseía una auctoritas extraordinaria, puesto que la asamblea residía en un sacro templum, bajo la mirada de los dioses. No obstante, durante el primer siglo del principado romano, el concepto de auctoritas y sus diferencias y equilibrios respecto a las nociones de imperium y potestas cambian radicalmente (Domingo, 1997, p. 188). El Emperador Octavio César Augusto, hijo adoptivo de César y fundador del Principado, aleccionado por el fracaso de su antecesor, declaró explícita y solemnemente su deseo de restaurar el orden republicano del viejo estado romano, aunque reservándose discretamente amplias facultades que le proveerían a él y a sus sucesores el gobierno casi ilimitado del Estado y del Imperio romano².

Augusto se presenta así como el salvador de la libertas y de la res publica respecto a las facciones que habían convertido el gobierno impersonal del populos en el dominio de unos hombres sobre otros. Roma pasó entonces a ser gobernada por un poder que, a medida que transcurría el Imperio, se hacía cada vez más personal. Pero siendo intolerable para las ideas republicanas que un solo hombre mandara sobre la multitud, se recurrió al artificio de hacer del hombre que

2 A propósito de este nuevo periodo, Wolfgang Kunkel (1996) en su texto sobre Historia del derecho romano establece que la nueva ordenación de la constitución republicana otorgaba amplias facultades políticas a Augusto, representante del poder monárquico, que, no obstante, contradecían los preceptos del derecho constitucional republicano (pp. 56-57). Augusto no quería ser considerado como un soberano designado constitucionalmente, sino como el primer ciudadano - princepsde una ciudad libre. De esta manera, Augusto gozaba de un extraordinario reconocimiento político - auctoritas - al lado de los funcionarios encargados del gobierno republicano, quienes eran sus empleados particulares. Así las cosas, la dirección y la gestión de los asuntos públicos, que otrora recaían sobre los órganos constitucionales, recaerían, en adelante, sobre los hombros de Augusto. 
ejercía el gobierno algo más que un hombre y, en consecuencia, Octavio se hizo augusto, esto es, sacro, santo, digno de veneración. De esta manera, en la persona de emperador se realzó más su auctoritas que su potestas hasta el punto de ser reconocido por la dignitas que provenía de su carácter de Augusto (García, 1981, p.41) ${ }^{3}$. De este modo, la restauración de la república significó, en realidad, la creación de un poder monárquico que no estaba contemplado al interior de la constitución, sino al exterior de ella misma: "la creación de Augusto es tan solo inteligible como un poder fiduciario, pues se encontraba fuera del orden republicano y estaba llamado a protegerlo y completarlo" (Kunkel, 1996, p. 56). Augusto había modificado severamente el orden jurídico romano al otorgarles labores legislativas, propias de los comicios, a los patres del Senado que -revestidos de auctoritas y no de potestas - crearían, en adelante, el derecho por disposición del Emperador (Domingo, 1997, p. 188; Kunkel, 1996, p. 60). D’Ors sostiene que este giro en la actividad jurídico-política constituye un reflejo evidente de la confusión entre auctoritas y potestas: Octavio Augusto pretendía gobernar la república romana más con auctoritas que con potestas.

De este modo, la auctoritas pasó a convertirse en un poder superior a lo que ordinariamente suponía: "la función legislativa que correspondía a la potestad de los magistrados populares pudo traspasarse a la autoridad del Senado, y luego, dada la sumisión de la autoridad senatorial a la del Príncipe, acabó por atribuirse de hecho a este" (D’Ors, 1980, p. 239). En otras palabras, mientras la constitución republicana conservaba una existencia meramente artificial que se desintegraba progresivamente, el príncipe agrupaba distintas atribuciones ilimitadas sobre toda la organización estatal que se perfeccionarían cada vez más (Kunkel, 1996, p. 61). En efecto, en las etapas subsiguientes a esta estructuración, conformadas por los reinados de Claudio, Domiciano y, especialmente, Adriano, marcharían paralelamente el despotismo imperial y la deificación del emperador,

3 Manuel García Pelayo (1981, p. 42) enseña que en la deificación del emperador romano intervino además del reconocimiento de la auctoritas de Octavio, la difusión en Roma, especialmente a través del Carmen saeculare de Horacio, y de las Églogas, de Virgilio, del mito oriental de un reino venidero que cerraría la historia dando una forma definitiva y feliz a la humanidad. Pero este reino no podía ser construido por la fuerza humana, sino únicamente por un hijo del cielo. De ahí que para los pueblos del Imperio romano cada emperador se transfigurara en el ser divino que traería el reino esperad. 
como si solo bajo el supuesto de que este fuera un dios pudiera encontrarse justificación a tan inmenso poder personal.

D’Ors afirma que durante el principado de Adriano, la confusión entre auctoritas y potestas alcanza su mayor vigor con la aparición de los rescriptos: el nuevo papel de la Oratio principis y la codificación del Edicto 4 . El bajo imperio sucede posteriormente al principado romano y, por consiguiente, la combinación, o mejor aún, la confusión entre auctoritas y potestas se presenta de un modo tan complejo como indiscernible. Diocleciano, emperador romano, debía realizar profundas transformaciones políticas y administrativas, para lo cual decidió encabezar una auctoritas sin precedentes. Esta auctoritas suprema del emperador no afectó al Senado, cuya dignidad se transformó en una nobleza hereditaria en la que solamente eran admitidos los altos funcionarios o los ricos terratenientes capaces de pagar los elevados impuestos derivados de dicha dignidad (Grimberg \& Svanström, 1967, pp. 338-339). Las formas republicanas desaparecieron, entonces, del escenario romano y, en su lugar, la monarquía absoluta advino mediante la voluntad dominante del emperador. Diocleciano fue homenajeado en forma de adoratio, además de vestir ropas espléndidas y vivir en una especie de

4 Con los rescriptos - fuente principal de producción jurídica hasta Diocleciano- los juristas de la Cancillería imperial -revestidos de auctoritas prudentium - pasaron a depender directamente del emperador -revestido de potestas-. La Oratio principis, es decir, el discurso u orationes que el emperador enviaba para su aprobación por el Senado, no era sino una fuente de potestad producida por un órgano de autoridad. En efecto, la aprobación senatorial se había convertido en un trámite meramente formal, siendo la voluntad del emperador la que finalmente se imponía. Por último, el Edicto - fuente de potestas-, al codificarse en época de Adriano, se convirtió en un libro de autoridad. Es bien sabido que el derecho romano no era un derecho positivo, sino jurisprudencial, ya que las mismas leyes no creaban ius sino a través de la recepción jurisprudencial. Los juristas creaban el derecho. Dichos juristas, que solían ser bastante respetuosos y conservadores de la tradición de los prudentes que les habían precedido, realizaban las reformas jurídicas de acuerdo con las exigencias actuales y, para ello, se valían de la jurisdicción pretoria. Los juristas introducían las novedades en un Edicto, bien fuere para incorporar algo nuevo, bien fuere para suprimir algo existente, de acuerdo con los resultados obtenidos en la vida social. De esta manera, las transformaciones del derecho que se producían a partir de la jurisdicción eran, sin duda, más ágiles, efectivas y prudentes que la de los derechos legislados, cuyos progresos procedían de la derogatoria de las leyes mediante las mismas leyes que las reformaban. Durante el siglo II, el Edicto se estabilizó y dejó de presentar modificaciones apreciables. Por tal razón, el emperador Adriano decidió hacer una edición oficial y definitiva del Edicto pretorio denominado Edicto recepticio, que incorporó las disposiciones de varios siglos y otras novedades. El nuevo texto que fue aprobado por el Senado, dejó de ser, por tanto, una publicación anual, para convertirse en un libro oficial, inalterable y evasivo a toda transformación (D'Ors, 1980, pp. 238-240; Domingo, 1997, pp.188-189). La auctoritas expresaba, entonces, el poder último y supremo de establecer normas de acción vinculatorias. 
aislamiento como un rey de reyes persa. Los demás hombres se referían a él, mediante el término dominus (señor), además de otros títulos imperiales más tradicionales, haciendo alusión justamente a su carácter sagrado y divino (Cameron, 2001, p. 52).

Pero la auctoritas en manos del emperador también logró una función política determinante en el Imperio, toda vez que generó una exaltación del patriotismo romano, además del sentimiento de seguridad y conservación del Imperio por parte de sus pobladores respecto a las agresiones externas. De modo que la auctoritas se convirtió, al mismo tiempo, y por razones prácticas, en una potestas absoluta, cuyo ejercicio constante y prolongado residía únicamente en manos del emperador. Este asignó, por supuesto, algunas funciones imperiales a ciertos funcionarios que gozaban de importancia y riqueza, aunque sometidos a un severo esquema jerárquico, cuyo control y vigilancia residía en la autoridad suprema. Asimismo, se creó el Consejo de Estado, integrado por cuatro ministros de la administración civil y otro número de altos funcionarios, que en lo sucesivo asumieron el papel del Senado. El Imperio romano se desarrolló, entonces, bajo una burocracia fuerte y centralizada, cuya dirección recayó sobre la auctoritas del gobierno y sus funcionarios (Grimberg \& Svanström, 1967, p. 339). A la muerte de Diocleciano, Constantino asumió el poder del Imperio, bajo el mismo pretexto de sus antecesores: restaurar, renovar, y hacer renacer el antiguo esplendor y gloria de Roma (Ullmann, 2003, pp. 11-33; Grimberg \& Svanström, 1967, p. 339).

La renovatio Romae implicó la producción sin paralelo de edictos, leyes y decretos, cuyo objetivo se orientaba a la protección del Imperio y sus súbditos 5 . Constantino, en su carácter de autoridad imperial, se mantuvo al igual que los demás emperadores por fuera y por encima del Imperio, lo cual incrementó magnífcamente sus poderes de gobierno. Pero el nuevo emperador, a diferencia del anterior, abrazó la causa de los cristianos, bien por razones políticas, bien por razones religiosas. En todo caso, Constantino supo reconocer en el cristianismo, o mejor, en el régimen de la cristiandad, la eficacia de su organización administrativa

5 Bajo los principios del derecho público romano, el emperador poseía toda la autoridad y el poder para crear la ley que. A partir de Constantino, la legislación imperial era la única fuente de derecho. El derecho público romano, a su vez, consistía en las cosas sacras, los sacerdotes y magistrados que administraban el bien común de los romanos. De modo tal que el derecho público estaba referido a la estructura y constitución del Imperio, esto es, al interés público. 
mediante la jerarquía y la dirección de obispos y sacerdotes elegidos por el pueblo. La Iglesia representaba un reflejo claro de la delimitación del poder que para entonces se había convertido en un estado dentro del Estado, aunque sujeta a la auctoritas del emperador, quien protegió su unidad contra distintas amenazas.

\section{Auctoritas en la praxis jurídico-política medieval}

LA CONFUSIÓN ENTRE AUCTORITAS Y POTESTAS logró un desarrollo mayor durante el gobierno papal de la Edad Media o, mejor, un nuevo contenido basado en la organización eclesiástica del ordo mundi (Ullmann, 1971, pp. 61-89; Wolkmer, 2008, pp. 17-21). Al igual que en el principado romano, en el periodo medieval la noción de auctoritas se caracterizó por su indivisibilidad que, por definición, y a diferencia de la potestas, sí era susceptible de división. Dicha característica resulta evidente, ya que las cuestiones de derecho público romano se aplicaron con igual fuerza a la Iglesia cristiana, bajo la cual confluyeron las ideas monoteístas cristianas y los principios monárquicos. De ahí que la auctoritas solo pudiera ser poseída y ejercida plenamente por un hombre, esto es, el papa. Los emperadores romanos habían cambiado de carácter cuando dejaron de considerarse emperadores divinos en la tierra para pasar a ser emperadores por la gracia de Dios, a quien reconocían como la única autoridad de la que se derivaba su poder. Este giro en la comprensión de la autoridad secular se debió no solo a la influencia de la doctrina paulina, sino también al reconocimiento de la gracia de Dios, entendida como un don o un regalo divino del que se derivaba la capacidad y los atributos del gobierno secular.

Esta nueva perspectiva jurídico-política justificó, en consecuencia, la plenitud del poder papal (Ullmann, 1971, pp. 61-65) y la idea concomitante según la cual el papa era la única autoridad mediadora entre Dios y el hombre, es decir, su representante en la tierra. El papa, en calidad de poseedor de los poderes petrinos, tenía, por lo tanto, el derecho a juzgar acerca del ejercicio de los poderes divinos que habían sido concedidos a reyes y príncipes seculares. Pero el papa además de mediar entre el cielo y la tierra, entre Dios y el rey, tenía en sus manos la administración total de la Iglesia que, al mismo tiempo, incluía el gobierno secular que se ejercía en su interior. Por esta razón, el papa presumía su poder de 
solicitar una rendición de cuentas al poder secular, ya que debía responder ante Dios por las acciones emprendidas en la tierra:

¿quién más que el papa podría estar en situación de decir si el rey se había mostrado digno o no de la confianza divina? ¿Si el rey había cumplido cabalmente con los deberes que la gracia divina había exigido de él al concederle la capacidad de gobernar? (Ullmann, 1971, p. 62)

El papa se concebía, pues, como el garante del bienestar de la ecclesia nobis commissa ("Iglesia a nos encomendada [es decir, al papa]"), que dependía estrictamente del desempeño correcto del rey respecto a los deberes con y para la Iglesia. Ahora, la gracia divina concedida al poder secular por intermedio del papa no generaba únicamente favores divinos, sino también consecuencias jurídicas importantes. En virtud de la gracia en favor nuestro, don de la gracia, la gracia especial ${ }^{6}$ del papa se obtenía o se perdía el privilegio de gobernar por parte de reyes y príncipes, quienes creían, a su vez, que su reino había sido confiado por la gracia Dios.

Esta concesión divina justificó, entonces, la autoridad suprema del papado medieval y la sujeción del poder secular a dicha autoridad: "que todos se sometan a las autoridades establecidas, pues no hay autoridad que no provenga de Dios, y las que existen, por Dios han sido constituidas" (Epistola a los romanos 13,1). De modo que el poder en la esfera pública se entendió, en adelante, como un favor de Dios mediado y transmitido únicamente por la autoridad del papa. El pontífice desarrollaba, pues, acciones concretas bajo su auctoritas sacrata y basándose en las formas paulinas, a saber: decidía sobre la definición de lo bueno y lo malo; asimismo sobre lo que era preciso o no exterminar en el mundo cristiano. El papa era el único capaz de pronunciarse sobre el mal, ya sea por el carácter de "piedra" que fundamentaba la "Iglesia", o bien por su carácter de gobierno pretino. El príncipe, por su parte, era el vengador que empuñaba la espada secular, diferenciándose claramente de quienes empuñaban la espada espiritual. Sin embargo, una y otra espada pertenecían a la Iglesia, toda vez que el príncipe actuaba conforme a las disposiciones de la Iglesia: su carácter era meramente funcional dentro del marco cristiano (Ullmann, 1971, p. 66; Berman, 1996, pp. 95-129). En suma, la auctoritas pertenecía al papa como universalis monarcha (rey sobre todo), quien ejercía el universale regimen (gobierno universal), porque, en tanto 
punto de intersección entre el cielo y la tierra, conocía exactamente lo que era útil o inútil para toda la Iglesia, pudiendo canalizar dicho saber mediante las normas coercitivas, esto es, en virtud de la ley (Ullmann, 1971, pp. 68-69).

\section{Auctoritas en la praxis jurídico-política moderna y contemporánea}

El Estado moderno occidental naCe, pues, de la lucha entre el poder espiritual y el poder secular por la auctoritas y, en consecuencia, por la plenitud del poder. Según Harold Berman (1996, p. 123), esta comprensión de la auctoritas sacrata como autoridad suprema y ordenadora de los asuntos espirituales y de las cuestiones temporales - gestada desde la misma Iglesia y en su propio interiorcausó el moderno Estado occidental, cuyo primer ejemplo fue, paradójicamente, la Iglesia misma. Bertrand de Jouvenel (1957) coincide con Berman al afirmar que la autoridad monopolística encuentra su origen en la Iglesia y no en el orden secular. De ahí que "la concentración de autoridad [papal] ha servido de modelo a las que se han producido en el campo político. Es evidente. La noción de majestad 'plena y redonda' ha sido restablecida por los papas" (Jouvenel, 1957, p. $310)^{7}$. Entre los objetivos de la revolución papal se advierten, en efecto, la eliminación del carácter y la función religiosa de la suprema autoridad política que, en adelante, se encargaría únicamente de gestionar los asuntos del gobierno secular. La Iglesia había despojado a los reyes y los emperadores de la competencia espiritual que habían ejercido en la antigüedad. De manera que solo el clero, encabezado por el papa, tenía competencia en los asuntos espirituales. Al igual que los emperadores romanos, el papa como autoridad y legislador supremo del cuerpo cristiano estaba por fuera y por encima de la Iglesia, lo cual confirmaba la ausencia de vínculos entre la Iglesia -que le había sido confiada- y él mismo. La fuente de autoridad del papa no residía en su antecesor, sino únicamente en San Pedro (Ullmann, 1971, p. 73). La Iglesia tenía, por consiguiente, el carácter de un Estado-Iglesia (Kirchenstaat), una comunidad espiritual que ejercía competencias temporales bajo una autoridad superior que decidía sobre el interés público bajo la gestión de diversas instituciones, funcionarios y cuerpos normativos.

$7 \mathrm{Al}$ respecto, véase también: Laurent, 2005. 
Después de Gregorio VII, la Iglesia adoptó, en sentido estricto, las características más sobresalientes del Estado moderno, afirmándose como una autoridad independiente, jerárquica y pública, y ejerciendo ella misma el pleno de los poderes jurisdiccionales, legislativos y administrativos. Dichos poderes eran esenciales para el mantenimiento del papado, teniendo en cuenta, ante todo, su carácter de institución gubernamental y supranacional. De manera que la fuente de su poder residía no solo en los textos y criterios teológicos, sino también, y más que nada, en el derecho canónico, concebido como un medio para la realización de los objetivos del cuerpo cristiano. La Iglesia poseía, en efecto, la suma total de los atributos jurisdiccionales, a través de los cuales podía interpretar y aplicar sus propias leyes mediante una jerarquía judicial que culminaba en la curia papal. De forma análoga a otros sistemas jurídicos seculares, el papado profería distintos decretos con fuerza vinculante, los cuales contenían un destinatario, un mandato de hacer o no hacer, una sanción y, finalmente, eran promulgados por una autoridad dotada con capacidad para emitir disposiciones obligatorias, cuya validez era universal en virtud del estatus del papado como epítome o quintaesencia de la Cristiandad (Ullmann, 1971, pp. 70-71; Berman, 1996, p. 124). La producción legislativa del papado durante el periodo medieval fue extraordinaria, en contraste con otros gobiernos de la época: los decretos contenían una redacción precisa, así como su interpretación, discusión y ejecución.

De ahí que el derecho canónico prevaleciera sobre el derecho romano, cuya aplicación era meramente subsidiaria, esto es, cuando se presentaba una inexistencia o laguna en el derecho divino (Ullmann, 1971, pp. 71-73). La Iglesia asimismo realizó distintas actividades administrativas, pues fijó impuestos a sus súbditos en forma de diezmos y otros gravámenes, y registró y sistematizó la población mediante los certificados de bautismo y de defunción. Mientras el bautismo confería una especie de ciudadanía, la excomunión decretaba una forma de privación de la ciudadanía.

Posteriormente, la autoridad del papa en la tierra se desplaza gradualmente al monarca. Algunos autores establecen que el proceso de integración y cambio de la organización cristiana a la modernidad estatal se origina bajo la formación de reinos, repúblicas, principados y tiranías en Italia durante los siglos XII a XV; otros, en cambio, sitúan dicho proceso a partir del surgimiento de los tres poderosos Estados nacionales europeos, a saber: Inglaterra, Francia y España -bajo 
Enrique VII (1485-1509); Luis XI (1461-1483) y los reyes católicos, Isabel de Castilla y Fernando de Aragón (1479-1516)-. La hipóstasis del Estado moderno y del soberano se lleva a cabo mediante la subrogación de un orden concreto -que otrora era dictado y protegido por el Imperio romano en la figura del emperador y, posteriormente, en la imagen del papa cristiano- y la transposición teológica de una serie de conceptos y atributos que permitieron erigirlo como la entidad suprema del orden telúrico (Fueyo, 1953, p. 377). Entre dichos atributos, propios de la evolución jurídico-política romana, se encuentra aquel según el cual existe un soberano, auctor de todas las normas, solus conditor legis ("legislador único"), y fuente de todos los derechos particulares. En palabras de Jouvenel (1957), esta idea tendrá ocasión únicamente a partir del siglo XII, ya que durante los siglos precedentes a la reaparición de esta idea romana el monarca se concibe exclusivamente como juez y no como legislador.

De modo que el objetivo fundamental de la modernidad consistió en la restauración de la concepción imperial de un solo jefe monopolizador de la autoridad que goza, por consiguiente, de la plena potestas. Los soberanos de Inglaterra, Francia y España mandarían únicamente sobre sus súbditos, declarándose en consecuencia como los emperadores de sus reinos. Según Jouvenel (1957): "son estos 'pequeños emperadores' los que harán prosperar la monopolización de la autoridad" (pp. 308-311). La autoridad en manos del soberano continúa, no obstante, reclamando la amplitud e inmediatez de sus mandatos sobre el orden humano respecto a otros poderes que amenazan su dominación. Esta subversión respecto a otras autoridades configura, pues, la historia misma de la soberanía. Jouvenel define la soberanía como el poder absoluto y total en todos los sentidos en que los canonistas hablan de la plenitud del poder. El soberano es supremo y superior, porque no existe ninguna otra autoridad que se iguale a su dignidad. Asimismo, su autoridad y poder son ilimitados en el tiempo y absolutos sobre todas las cosas que conforman la organización política. La soberanía consiste, pues,

en no tener por encima de sí ni a un hombre ni a una ley. Este poder es absoluto y por encima de todo límite. El príncipe está exento de las leyes, decía la ley, y desde entonces la ley es lo que quiere el príncipe. (Albericus Gentilis, citado en Jouvenel, 1957, p. 323)

En el mismo sentido, Jean Bodino (1973, p. 51) afirma que toda organización política precisa de un poder supremo que haga las leyes y confiera la investidura a 
los magistrados, no estando él mismo sujeto a ninguna ley, excepto a las de Dios y a las de la naturaleza. Durante el siglo XX se asiste nuevamente a la confusión entre auctoritas y potestas bajo las dictaduras totalitarias de Alemania y Rusia. Al igual que el Imperio romano, el fascismo y el nacionalismo hacen emanar la autoridad de un solo hombre, cuya promesa radica en la creación de un nuevo orden -sin ignorar, obviamente, sus diferencias-. Adolf Hitler, por ejemplo, empleaba numerosas veces el término revolución para referirse a la destrucción del orden existente y los planes del "partido" de construir una nueva Alemania (Overy, 2012, p. 83). La restauración de un nuevo orden es, pues, el pretexto que funda la relación entre auctoritas y potestas, la cual se produce desde los tiempos del principado, pasando por la revolución papal y real, hasta las dictaduras totalitarias contemporáneas. En el mismo sentido, Schmitt (2004 [1934]) afirma en su texto $E l$ Fübrer defiende el derecho, que a diferencia de la mayoría que omite por temor o desidia las advertencias de la historia, "el Führer, en cambio, toma en serio las advertencias de la historia alemana. Esto le da el derecho y la fuerza necesarios para fundar un nuevo Estado y un nuevo orden" (Schmitt, 2004, p. 115). Ahora se trata del poder personal y el carisma del Jefe, cuya adoración por parte de muchos determinó su reconocimiento y obediencia voluntaria ${ }^{8}$.

La superpersonalidad de Hitler, Stalin y Mussolini constituía la causa de su autoridad y el efecto de su poder sobre las masas y los individuos, ahora convertidos en objetos sin ningún valor. Hitler argüía vehementemente que la finalidad principal del Estado radicaba en elevar a las personalidades superiores a posiciones de autoridad y Stalin insistía en que el pueblo ruso necesitaba un zar, esto es,

8 Además de los estudios jurídico-políticos de Carl Schmitt acerca de la decisión y la excepción como manifestaciones objetivas e inmediatas de la autoridad del soberano, Theodor W. Adorno, Else Frenkel-Brunswik, Daniel Levinson y R. Nevitt Sanford también teorizaron el fenómeno de la autoridad y sus distintas manifestaciones, a partir de la búsqueda y la comprensión de los factores socio-psicológicos que hacen posible la aparición de individuos potencialmente fascistas. Esta investigación constituye un avance frente a los análisis del psicoanalista Erich Fromm, quien investigó agudamente las causas y los alcances del carácter autoritario, entendido como la base de la personalidad que impulsa al individuo a obedecer y servir a determinadas autoridades exteriores. Fromm (2008) advierte, en efecto, que el carácter autoritario constituye un factor psicológico ineludible para comprender el alcance y significado del autoritarismo, ya que dicho carácter no solo determina el pensamiento y la acción del individuo, sino también su adhesión incondicionada a determinadas autoridades exteriores. Por su parte, Adorno et al. (2006) avanzan en el análisis sobre los fascistas potenciales, cuyos rasgos facilitan la difusión de los regímenes autoritarios. 
el liderazgo de un solo hombre, de modo que el poder de ambos dictadores carecía de toda traba y limitación. El cargo del Führer bajo el nuevo orden político comprendía, sin embargo, algo más que la función del presidente o el primer ministro, e incluso, la misión del guía, el jefe o el líder, toda vez que aludía a la promesa de un legislador o profeta generado por la historia misma y destinado a conducir al pueblo hacia el futuro, sin ninguna dilación ni vacilación (Overy, 2012, pp. 198-199). Los regímenes totalitarios, al igual que el principado romano, preservaron, no obstante, la estructura constitucional. En efecto, tanto el sistema hitleriano como el régimen soviético, lejos de operar bajo un despotismo puro y simple, actuaron bajo la apariencia formal de los procedimientos, las normas constitucionales y las instituciones legales. Sin embargo, la constitución no limitaba realmente a ninguno de los dictadores, quienes advirtieron la necesidad de crear formas jurídicas extraconstitucionales irreconciliables con las disposiciones constitucionales. De modo que ambos dictadores estaban por fuera de la ley y, no obstante, creaban la ley. Hitler, por ejemplo, promulgaba profusos decretos y directrices en nombre propio, los cuales adquirían fuerza de ley, incluso mayor a cualquier ley oficial del Parlamento, porque el resto del sistema los aceptaba como categorías especiales de leyes. Hitler actuaba, entonces, como el único legislador, sin la necesidad de consultar con los ministros ni buscar la aprobación del Reichstag. En su trabajo titulado Dictadores, Richard Overy señala que durante la guerra se expidieron 659 órdenes legislativas importantes, de las cuales 72 fueron leyes formales, 241 fueron decretos del Fübrer y 173 órdenes del Führer (Overy, 2012, pp. 99-103, 109). La creación jurídica era, pues, el resultado de la voluntad habitual del líder.

Las confusiones teóricas y prácticas entre auctoritas y potestas alcanzan a destruir no solo la esencia misma del derecho, al subordinarlo a la soberanía y el interés del Estado, haciéndolo emanar del Imperio, la República, el Estado o la Nación, cuyos trazos se distinguen desde Roma hasta nuestra actualidad; también, y más exactamente, alcanzan a destruir la vida humana. El paralelismo entre auctoritas y potestas sería incompleto si se limitara exclusivamente a señalar los efectos de creación y destrucción del derecho, sin advertir, al mismo tiempo, las consecuencias letales que dicha relación jurídico-política produce sobre la vida misma. A diferencia de Agamben, quien considera la auctoritas como la forma política mediante la cual se suspende o reactiva la potestas, aprehendiendo la 
vida mediante una violencia inaudita, deberá afirmarse, más bien, la auctoritas como la forma política mediante la cual se amplifica, extiende y perfecciona la potestas respecto a la vida humana, al punto de aplastarla mediante la saturación y el exceso de poder porque la relación teórica e histórica entre las nociones de autoridad y poder ha generado no solo el aplastamiento de las naciones declaradas como enemigas, sino también la crueldad difusa, cotidiana, pública, así como la bajeza y la sumisión sin límites respecto de una autoridad capaz de manejar a poblaciones enteras como objetos sin valor (Weil, 2007, p. 259).

Todos esos rasgos recuerdan de forma sorprendente a las dictaduras totalitarias modernas, cuya máxima expresión implica el poder absoluto de un hombre sobre los demás hombres convertidos ahora en masas superfluas. El acrecentamiento de la potestas por parte de la auctoritas significa, pues, que los dispositivos de poder, incluida la violencia, se expanden y se perfeccionan como medios legítimos de gestión sobre la población. En palabras más claras,

la legitimidad del poder se traduce en la legitimidad de la violencia. En otras palabras, el empleo de la violencia se hace posible, en mayor o menor grado, por la creencia en la legitimidad que transforma el poder en autoridad. (Stoppino, 2011, p. 123)

La transfiguración del poder en autoridad y, por consiguiente, su relación con la violencia es algo más que una curiosidad teórica, dado que la creencia férrea en la legitimidad del poder ha generado históricamente una violencia inaudita sobre la vida, hasta el punto de reducirla a una vida desprovista de toda humanidad. Esta afirmación toma lugar en las cacerías de brujas y en los linchamientos de los excluidos y de los extraños, así como en los fanatismos políticos y religiosos de todas las épocas; también en el fascismo y el nacionalismo europeos, los cuales propagaron una violencia sin precedentes (Stoppino, 2011, p. 123).

En este sentido, Arendt (2010b) afirma que

la experiencia de los campos muestra que los seres humanos pueden ser transformados en especímenes del animal humano y que la "naturaleza" del hombre es solamente "humana" en tanto que abre al hombre la posibilidad de convertirse en algo altamente innatural. (p. 610)

En este punto, lo que debe comprenderse es que el verdadero espíritu puede ser destruido sin llegar siquiera a la destrucción fisica del hombre; y que desde luego el espíritu, el carácter y la individualidad, 
bajo determinadas circunstancias, solo parecen expresarse por la rapidez o la lentitud con la que se desintegran. (Arend, 2010b, p. 593)

El exceso de fuerza como resultado de la unión entre auctoritas y potestas produce, pues, vidas saturadas de violencia. Porque

la violencia es seguramente una pequeña muestra del peor orden posible, un modo terrorífico de exponer el carácter originariamente vulnerable del hombre con respecto a otros seres humanos, un modo por el que la vida misma puede ser eliminada por la acción deliberada de otro. (Butler, 2006, p. 55)

\section{Conclusiones}

El ANÁLISIS BINARIO DE LAS NOCIONES de auctoritas (autoridad) y potestas (poder), mediando entre estas la violencia, permiten repensar categorías que, pese a su desconocimiento en los estudios del derecho, resultan decisivas para comprender el sentido y los fundamentos del derecho, así como sus implicaciones en el mundo de la vida. A diferencia de las distintas investigaciones filológicas, filosóficas, políticas y jurídicas que intentan definir las nociones de autoridad y poder a partir de su radical distanciamiento, diferencia y oposición, con miras a restaurar la tradición, es preciso entender ambas nociones en virtud de sus paradójicas afinidades, o lo que es lo mismo, desde sus posibles combinaciones, buscando descubrir, al mismo tiempo, el fundamento oculto de dicho nexo, a saber: la violencia y sus efectos en el derecho.

Las categorías autoridad, poder y violencia resultan inevitables para examinar el derecho en general y la filosofía jurídico-política en particular, a partir de su complejidad radical, esto es, desde sus enigmas, antinomias, anomalías y crisis teórico-prácticas. Dichos vocablos resultan ahora complemente abstractos y desconocidos no solo para la tradición, sino también, y más exactamente, frente a los avatares de la vida contemporánea. Por esta razón, se hace preciso investigar ahora los grandes conceptos, las palabras de larga duración en nuestros léxicos jurídico-políticos, "no como entidades en sí cerradas, sino como 'términos', marcas de confín, y al mismo tiempo, lugares de superposición contradictoria, entre lenguajes diversos" (Esposito, 2006, p. 8). En efecto, el sentido de las nociones y particularmente de la categoría de autoridad implica algo más que su mera estratificación epocal y disciplinar, ya que dicha noción se prolonga en una línea de 
tensión con otros términos, la mayor de las veces análogos, tales como fuerza, reconocimiento, poder, guerra y, especialmente, violencia, que son centrales en la comprensión del derecho en relación con el mundo de la vida social.

Bajo este presupuesto, la revisión teórica no es fin en sí misma, por cuanto la confusión entre auctoritas y potestas no solo ha legitimado la violencia como medio de fundación y conservación del Estado y el derecho, sino también la disposición permanente de la vida de los individuos mediante la coacción. Por esta razón, ningún tema resulta más apremiante y, al mismo tiempo, más difícil de tratar que el de la violencia jurídico-estatal sobre la vida. Negar la posibilidad crítica a los fundamentos del poder, la autoridad y la violencia parece aceptar sin más la condena de una sociedad apática a todo tipo de fuerza bien sea jurídica, social o política, lo cual reproduce y perpetúa indefinidamente aquella guerra e injusticia que no encuentra otra respuesta sino a través de la violencia legítima, que por ello no deja ser violencia y que, en consecuencia, condena, detiene, expulsa, excluye, mata o simplemente abandona. El asunto de la violencia se ha vuelto pues forzoso para toda investigación que pretenda comprender agudamente el derecho en constelación con otros términos y fenómenos de la praxis política (Nancy, 2001, p. 23; Echeverría, 2011, p. 309). De ahí que la actualización de los términos jurídicopolíticos de auctoritas y potestas constituya una tarea apremiante, puesto que la creencia férrea en la legitimidad del poder y la protección de la autoridad ha generado de manera sistemática una violencia letal sobre la vida, hasta el punto de reducirla a una vida desprovista de toda humanidad.

Así pues, es necesario investigar críticamente el origen y los sentidos de las nociones mencionadas, sus fracturas, giros y escisiones, cuyos efectos han consistido en admitir una autoridad capaz de repeler toda acción destinada a destruirla mediante la administración, el control e, incluso, la eliminación de la vida humana. Bajo este escenario de poder y sometimiento, la autoridad representativa del orden, quien surge, de pronto, como un guerrero o un jefe en nombre de la comunidad vulnerable, amplifica los dispositivos de poder, incluida la violencia, extendiéndolos y perfeccionándolos no solo respecto a los enemigos, sino también, y más que nada, respecto a sus propios ciudadanos:

La legitimidad del poder se traduce en la legitimidad de la violencia. En otras palabras, el empleo de la violencia se hace posible, en mayor o menor 
grado, por la creencia en la legitimidad que transforma el poder en autoridad. (Stoppino, 2011, p. 123)

La gran máquina constituye, pues, un mecanismo de poder extraordinario cuya autoridad reside en su capacidad de triturar el espíritu humano: "el hombre que se encuentra así capturado es como un obrero atrapado por los dientes de una máquina. No es más que una cosa desgarrada” (Weil, 2007 p. 34). En este punto, basta recordar las palabras de Friedrich Nietzsche para temer del deseo de las masas que gritan invocando al viejo Leviatán, el nuevo ídolo de seguridad, orden y protección.

\section{Referencias}

Adorno, T.; Frenkel-Brunswik, E.; Levinson, D. \& Sanford, R. (2006). La personalidad autoritaria (prefacio, introducción y conclusiones). Empiria. Revista de Metodología de las Ciencias Sociales, 12, pp.155-200.

Agamben, G. (2004). Estado de excepción. Homo sacer II, I (Trad. A. Gimeno). Valencia: Pre-Textos.

Agamben, G. (2006). Homo sacer. Elpoder soberano y la nuda vida (Trad. A. Gimeno). Valencia: Pre-Textos.

Arendt, H. (1996). ¿Qué es la autoridad? En: Entre el pasado y el futuro. Ocho ejercicios sobre la reflexión politica. Barcelona: Península.

Arendt, H. (2010a). Sobre la violencia (Trad. G. Solana). Madrid: Alianza.

Arendt, H. (2010b). Los origenes del totalitarismo (Trad. S. Giner). Madrid: Alianza.

Benveniste, E. (1969). Vocabulario de las instituciones indoeuropeas (Trad. M. Armiño). Madrid: Taurus.

Berman, J. (1996). La formación de la tradición jurídica de Occidente (Trad. M. Utrilla de Neira). México D. F: Fondo de Cultura Económica.

Bodino, J. (1973). Los seis libros de la República (Trad. P. Bravo). Madrid: Aguilar.

Butler, J. (2006). Vida precaria. El poder del duelo y la violencia (Trad. F. Rodríguez). Buenos Aires: Paidós.

Cameron, A. (2001). El bajo imperio romano (Trads. I. Utande \& P. Carbajosa). Madrid: Encuentro. 
Casinos, J. (1999). El dualismo auctoritas-potestas como fundamento de la organización y del pensamiento políticos de Roma. Polis. Revista de ideas y formas políticas de la Antigüedad Clásica, 11, pp. 85-109.

Clemente, A. (2009). El significado unitario del término auctoritas en sus origenes. (Tesis de grado, Universidad de Castilla-La Mancha, Toledo, España). Recuperada de https://www.educacion.gob.es/teseo/imprimirFicheroTesis.do? fichero $=21842$

D’Entrèves, A. (2001). La noción de Estado. Una introducción a la Teoria Politica (Trad. R. Punset). Barcelona: Ariel.

D’Ors, A. (1980). Nuevos papeles del oficio universitario. Madrid: Rialp.

D’Ors, A. (1984). Auctoritas-authenticum. Estudios clásicos, 88, pp. 375-382. Recuperado de http://interclassica.um.es/index.php/interclassica/investigacion/hemeroteca/e/estudios_clasicos/numero_88_1984/auctoritas_a_ thent_a_authenticum

Domingo, R. (1997). El binomio "auctoritas-potestas" en el derecho romano y moderno. Persona y derecho. Revista de fundamentación de las Instituciones Jurídicas y de Derechos Humanos, 37, pp. 183-196.

Esposito, R. (2006). Categorias de lo impolitico (Trad. R, Raschella). Buenos Aires: Katz.

Fueyo, J. (1953). El sentido del Derecho y el Estado moderno. Anuario de Filosofia del Derecho, 1, pp. 381-395.

Fueyo, J. (1961). El principio de autoridad en la crisis de la sociedad contemporánea. Revista de Estudios Políticos, 115, pp. 43-64.

García, M. (1981). Los mitos políticos. Madrid: Alianza.

García, M. (1983). Idea de la política y otros escritos. Madrid: Centro de Estudios Constitucionales.

Grimberg, C. \& Svanström, R. (1967). Roma (Trad. T. Riaño). Bogotá: Círculo de Lectores.

Grimmal, P. (1999). La civilización romana. Vida, costumbres, leyes, artes (Trad. J. Serra). Barcelona: Paidós.

Ihering, R. (2001). El espiritu del derecho romano. México D. F: Marcial Pons. Jouvenel, B. (1957). La soberania (Trad. L. Benavides). Madrid: Rialp. 
Kunkel, W. (1996). Historia del derecho romano (Trad. J. Miquel). Barcelona: Ariel.

Laurent, P. (2005). Teología politica absolutista en la génesis del derecho moderno. Lima: Pontificia Universidad Católica de Perú.

Mommsen, T. (2003). Historia de Roma. Libros Iy II. Desde la fundación de Roma hasta la reunión de los Estados Itálicos. (Trad. A. García). Madrid: Turner.

Overy, R. (2012). Dictadores. La Alemania de Hitler y la Unión Soviética de Stalin (Trad. J. Beltrán). Buenos Aires: Tusquets.

Passerin D'Entreves, A. (2001). La noción de Estado. Una introducción a la Teoría Política (Trad. R. Punset). Madrid: Ariel.

Ruiz, A. (2013). La violencia del derecho y la nuda vida. Medellín: Universidad de Antioquia.

Sartori, G. (1993). ¿Qué es la democracia? (Trad. M. González). México D. F.: Patria.

Schmitt, C. (1996). Teoria de la Constitución (Trad. F. Alaya). Madrid: Alianza.

Schmitt, C. (2004). El Führer defiende el derecho. En: Oretes, H. (Comp.). Carl Schmitt, teólogo de la politica (pp. 114-118). México D. F: Fondo de Cultura Económica.

Stoppino, M. (2011). Autoridad. En: Bobbio, N.; Matteucci, N. \& Pasquino, G. (Eds.). Diccionario de Política a-j (Trads. R. Crisafio, A. García, M. Martí, M. Martín \& J. Tula) (pp. 14118-14125). México D. F: Siglo XXI Editores. Ullmann, W. (1971). Principios de gobierno y política en la Edad Media (Trad. G. Soriano). Madrid: Revista de Occidente.

Ullmann, W. (2003). Escritos sobre teoría política medieval (Trad. M. Barbuto). Buenos Aires: Eudeba.

Weber, M. (1964). Economía y sociedad: esbozo de sociología comprensiva (Trads. J. Medina, J. Roura, E. Imaz, E. García \& J. Ferrater). México D. F: Fondo de Cultura Económica.

Weil, S. (2007). Escritos históricos y políticos (Trads. A. López \& M. Tabuyo). Madrid: Trotta.

Wolkmer, A. (2008). Historia de las ideas jurídicas. De la antigüedad clásica a la modernidad. México D. F: Porrúa. 